\title{
İnvajinasyon Nedeni ile Takip Ettiğimiz Hastalarda Cerrahi Tedavi Endikasyonu ile Ultrasonografi Bulguları Arasındaki İlişkinin Değerlendirilmesi
}

\author{
Murat KAYA 國, Murat KABAKLIOĞLU 國
}

Öz

Amaç: İki yaş altı çocuklarda cerrahi akut karının en önemli sebebi invajinasyondur. Bu çalışma cerrahi tedavi gereken hastalarla ultrasonografi (USG) bulguları arasındaki ilişkiyi göstermek için planlandı.

Gereç ve Yöntemler: Bu çalı̧̧maya Düzce Üniversitesi Tıp Fakültesi Araştırma ve Uygulama Hastanesi Çocuk Cerrahisi kliniğinde 01/01/2011-31/12/2020 tarihleri arasında takip edilen invajinasyon hastaları dahil edildi. Bilgiler dosya taraması şeklinde retrospektif olarak elde edildi.

Bulgular: Hastalarımızın ortalama yaşı 2,5 yaş idi ve çoğunun ishalin çok görüldüğü yaz aylarında başvurduğu görüldü. Hastaların çoğuna (98 hasta ve \% 62,8) USG'de target sign (hedef işareti) bulgusuyla tanı konuldu, 22 tanesi $(\% 14,1) 20 \mathrm{~mm}, 36$ hasta ise $(\% 23,1)>20 \mathrm{~mm}$ ölçümle invajinasyon tanısı aldı. İki yaş altında tanı alan hastaların $\% 50$ 'sinde USG'de hedef işareti bulgusuyla invajinasyon tanısı alırken bu oran $\geq 2$ yaş hastalarda 60 hasta $(\% 75)$ idi ve istatiksel olarak anlamlı bir fark vardı $(\mathrm{p}=0,04)$. Bu durum $<2$ yaş altındaki hastalardaki cerrahi tedavi gerekliliğinin daha fazla olması ile uyumlu bir bulguydu.

Sonuç: İki yaş altında USG'de özellikle $>20 \mathrm{~mm}$ ölçümle tanı alan hastaların cerrahi tedavi gerekliliği açışından diğerlerine göre daha yakın gözlemi gerekir. Opere edilmeyen hastaların ise çoğu hedef işareti bulgusuyla USG tanısı aldıkları için bunların gözleminde daha rahat davranılabilir.

Anahtar Kelimeler: İnvajinasyon; USG; cerrahi; medikal.

\section{Evaluation of the Relationship Between Surgical Treatment Indication and Ultrasonography Findings in Patients We Follow Up for Invagination}

\begin{abstract}
Aim: The most important cause of surgical acute abdomen in children under two years of age is intussusception. This study was planned to show the relationship between patients requiring surgical treatment and ultrasonography findings. Material and Methods: Intussusception patients who were followed up in Duzce University Medical Faculty Research and Application Hospital Pediatric Surgery Clinic between 01/01/2011-31/12/2020 were included in this study. The information was obtained retrospectively of file scanning.

Results: The average age of our patients was 2.5 years, and most of them were seen to apply in the summer months, when diarrhea is common. Most of the patients (98 patients and 62.8\%) were diagnosed with the target sign finding in USG. Twenty-two of the patients $(14.1 \%)$ were diagnosed with intussusception with a measurement of $20 \mathrm{~mm}$, and 36 patients $(23.1 \%)$ with a measurement of $>20 \mathrm{~mm}$. While $50 \%$ of patients diagnosed under two years of age were diagnosed with intussusception as a target sign on USG, this rate was 60 patients $(75 \%)$ in patients 2 years old, and there was a statistically significant difference $(\mathrm{p}=0.04)$. This was a finding consistent with the greater need for surgical treatment in patients under 2 years old.

Conclusions: Patients under the age of two who are diagnosed with a measurement of $>20 \mathrm{~mm}$ on USG, especially, should be observed more closely than others in terms of the need for surgical treatment. Since most of the non-operated patients are diagnosed with USG with target sign findings, they can be observed more comfortably in their observation. Key words: Intussusception; USG; surgery; medical.
\end{abstract}

1 Düzce Üniversitesi, Tıp Fakültesi, Çocuk Cerrahisi Anabilim Dalı, Düzce/Türkiye

Sorumlu Yazar / Corresponding Author: Murat KAYA, e-mail: drkayam@gmail.com Geliş Tarihi / Received: 24.05.2021, Kabul Tarihi / Accepted: 05.07.2021 


\section{GÍRIȘ}

Acile başvuran çocuk hastaların başvuru şikayetleri içerisinde karın ağrısı önemli bir yer tutar. Çocuk yaş grubunda yapılmış olan bir kohort çalışmada $<3$ gün süren karın ağrısı ile getirilen çocuk hasta prevalansı $\% 5,1$; ağrı süresi gözardı edildiğinde ise, $>2$ yaş çocuk yaş grubunda aynı oran \%8,1 bulunmuştur (1).

İnvajinasyon 6-9 aylık bebeklerde en sık olarak görülür ve aralıklı tekrarlayan karın ağrısı ve kusma atakları tipiktir. Ataklar arası dönemlerde ise bebek normaldir. Kusmaları başlangıçta safrasızken zamanla safralı hale gelir. Çilek jölesi şeklindeki kanlı dışkılama invajinasyon için tipiktir ve barsak nekrozunu gösterir. Dolayısı ile çilek jölesi şeklindeki dışkılama cerrahi tedavinin gerekliğine işaret eder. Geç dönemde başvuran hastalarda sağ üst kadranda ağrılı kitle palpe edilebilir ve lökositoz olur. İnvajinasyon tanıs1 ultrasonografi (USG) ile konulur; USG'de target sign (hedef işareti) ve yalancı böbrek görünümü tipik olarak görülür. Ağızdan beslenmenin kesilerek (iv) sivi tedavisi ve rektal uyaranlarla (tuşe ve lavman) hastaların çoğu cerrahi tedaviye gerek duyulmadan düzelir (2). Cerrahi tedavinin gerekli olabilmesinden dolayı, hastaların çocuk cerrahi uzmanı olan merkezlerde takip edilmesi önerilir. Tedavide non-invazivden invazive doğru gidilerek sırasıyla USG eşliğinde hidrostatik redüksiyon; pnömotik redüksiyon; skopi eşliğinde baryum/gastrografin redüksiyon ve cerrahi (elle redüksiyon ya da rezeksiyon+anastomoz) denenir.

Biz bu çalışma ile Düzce Üniversitesi Tıp Fakültesi Araştırma ve Uygulama Hastanesi Çocuk Cerrahisi kliniğinde 01/01/2011-31/12/2020 tarihleri arasında takip edilen invajinasyon hastalarını dosya taraması şeklinde retrospektif olarak inceleyerek invajinasyondaki cerrahi tedavi endikasyonu ile preoperatif USG bulguları arasındaki ilişkiyi ortaya koymayı amaçladık.

\section{GEREC VE YÖNTEMLER}

Retrospektif ve tanımlayıcı nitelikte olan bu çalışma için Düzce Üniversitesi Tıp Fakültesi Klinik Etik kurulundan onay alınmıştır (Tarih: 24/05/2021; Karar no: 2021/127). Düzce Üniversitesi Tıp Fakültesi Araştırma ve Uygulama Hastanesi Çocuk Cerrahisi kliniğinde 01/01/201131/12/2020 tarihleri arasında takip edilen invajinasyon hastaları incelenmiştir. Tüm hastalardan bilgilendirilmiş onam formları alınmıştır.

\section{Çalışmaya dahil etme kriterleri}

Bu çalışmaya Düzce Üniversitesi Tıp Fakültesi Araştırma ve Uygulama Hastanesi Çocuk Cerrahisi kliniğinde 01/01/2011-31/12/2020 tarihleri arasında takip edilen invajinasyon hastaları dahil edildi. Bilgiler dosya taraması şeklinde retrospektif olarak elde edildi. Aynı tarihler arasında başka tanılarla kliniğimizde tedavi gören hastalar ise çalışma dışı bırakıldı.

Hastanın yaşı, cinsiyeti, başvuru zamanı, ultrasonografi (USG) bulguları, operasyonun yapılıp yapılmadığı, eşlik eden cerrahi patoloji varlığı (Meckel, polip, duplikasyon, lenfoma, hemanjiom, lenfosarkom vb.) ve cerrahi sonrasi nüks olup olmadığı bulguları retrospektif olarak taranıp not edildi.

\section{İstatistiksel Analiz}

Elde edilen veriler istatistik paket programına kaydedilip analiz edildi. Bütün veriler bilgisayar ortamında SPSS
15.0 (SPSS, Inc, Chicago, Illinois, USA) istatistik programı kullanılarak değerlendirildi. Araştırmanın tüm verileri için öncelikle tanımlayıcı istatistikler uygulandı. Ölçümle belirlenen değişkenler için tanımlayıcı istatistikler; ortalama ve standart sapma şeklinde verildi. Kullanılan verilerin öncelikle normal dağılıma uygunluk testleri (Shapiro-Wilk testi) yapıldı Grup karşılaştırmalarında Kruskal-Wallis testi kullanıldı. Kategorik değişkenler Chi-square (Fisher's exact) testi ile karşılaştırıldı. P değeri $<0,05$ olanlar istatistiksel olarak anlamlı kabul edildi.

\section{BULGULAR}

Toplam 156 hastanın ortalama yaşı 2,5 $( \pm 2,4)$ yaş idi (min: 1 ay-max: 13 yaş). Hastaların yarısı kadın, yarısı ise erkekti (78 kadın, 78 erkek).

Hastaların en çok başvurduğu ay temmuz (toplam 24 hasta ve \% 15,4), en az başvurduğu ay ise kasım (toplam 2 hasta ve \% 1,3) idi. Hastaların en çok başvurdukları mevsim yaz ayları (toplam 68 hasta ve \% 38,5), en az başvurdukları mevsim ise güz ayları (toplam 18 hasta ve $\%$ 11,5) idi.

Hastaların 42 tanesinde (\% 26,9) cerrahi tedavi gerekti, 114 hastada $(\% 73,1)$ ise medikal tedavi yeterli oldu. Cerrahi tedavi gereken hastaların da 28 tanesinde (\% 66,7) ileoileal bölgede, 14 tanesinde $(\% 33,3)$ ise ileoçekal bölgede invajinasyon vard1.

Tüm hastaların sadece yedisinde $(\%$ 4,5) lead point (öncül neden) vardı. Bunlar da sıklık sırasına göre dört hastada Meckel divertiküliti, iki hastada apandisit ve bir hastada karsinoid tümör olarak saptandı.

Hastaların ultrasonografik tanıları değerlendirildiğinde çoğunluğunun hedef işareti $(\leq 10 \mathrm{~mm}$ invajinasyon bölgesi) olarak tariflendiği görüldü. Tüm hastaların 98 'i $(\% 62,8)$ USG'de hedef işareti bulgusuyla invajinasyon tanıs1 ald1, 22'si $(\% 14,1)$ USG'de 20mm invajinasyon bölgesi ölçülerek tanı aldı, hastaların sadece 36's1 $(\% 23,1)$ USG'de $>20 \mathrm{~mm}$ invajinasyon bölgesi uzunluğu ölçülerek tanı aldı.

Tüm hastaların 76'sı $(\% 48,7)<2$ yaş, 80'i ise $\geq 2$ yaş idi. Cerrahi tedavi gereken 42 hastanın ise 28 'i $(\% 66,7)<2$ yaş; sadece 14 ' $\ddot{u} \geq 2$ yaş idi. Cerrahi tedavi gerekliliği açısından $<2$ yaş hastalar ile $\geq 2$ yaş hastalar arasında istatiksel olarak anlamlı fark vard $1(\mathrm{X} 2=7,4 ; \mathrm{p}=0,05)$. Cerrahi tedavi gören $<2$ yaş hastaların 18 'inde $(\% 64,3)$ ileoileal bölgede, 10 hastada $(\% 35,7)$ ise ileoçekal bölgede invajinasyon vardı. Cerrahi tedavi gören $\geq 2$ yaş hastaların 10'unda $(\% 71,4)$ ileoileal bölgede, 4 hastada $(\%$ 28,6) ise ileoçekal bölgede invajinasyon vard1. İnvajinasyon bölgesi açısından $<2$ yaş hastalar ile $\geq 2$ yaş hastalar arasında istatiksel olarak anlamlı fark yoktu (X2=7,6; p=0,22) (Tablo 1).

İki yaş altında tanı alan toplam 76 hastanın 38'i (\% 50) USG'de hedef işareti olarak invajinasyon tanısı alırken bu oran $\geq 2$ yaş hastalarda 60 hasta $(\% 75)$ idi ve istatiksel olarak anlamlı bir fark vard $1(\mathrm{X} 2=20,9 ; \mathrm{p}=0,04)$ (Tablo 1). Yine cerrahi tedavi gereken hastalarda USG'de hedef işareti dışında, yani $20 \mathrm{~mm}$ veya fazlası bir invajinasyon bölgesi ölçümü verilerek tanı alanların sayısı 28 (\%66,7) iken; hedef işareti bulgusuyla USG tanısı alanların sayısı ise $14(\% 33,3)$ idi. Operasyon gerekmeyen hastaları ise çoğu $(84$ hasta ve $\% 73,4)$ hedef işareti bulgusuyla USG tanısı aldı. USG'de hedef işareti ile invajinasyon tanısı 
alıp cerrahi gerekmeyen hastalar ile cerrahi gereken hastalar arasında istatiksel olarak anlamlı bir fark vardı $(\mathrm{X} 2=36,8 ; \mathrm{p}=0,000)$. Yine benzer şekilde USG'de hedef işareti ile invajinasyon tanısı alıp cerrahi gerekmeyen hastalar ile cerrahi gereken hastalar arasında invajinasyon bölgesi açısından da istatiksel olarak anlamlı bir fark vard1 $(X 2=49,8 ; p<0,001)$. Ayrıca benzer şekilde USG'de hedef işareti ile invajinasyon tanısı alıp cerrahi gerekmeyen hastalar ile cerrahi gereken hastalar arasında başvuru mevsimi açısından da istatiksel olarak anlamlı bir fark vard $1(X 2=59,6 ; \mathrm{p}<0,001)$.

Tablo 1. 2 yaş altı ve üstü hastaların karşılaştırılması

\begin{tabular}{|c|c|c|c|c|}
\hline & & \multicolumn{2}{|r|}{ Yaş } & \multirow[b]{2}{*}{$\mathbf{p}$} \\
\hline & & $\begin{array}{l}<2 \text { yaş } \\
(n=76)\end{array}$ & $\begin{array}{l}\geq 2 \text { yaş } \\
(n=80)\end{array}$ & \\
\hline \multirow[t]{2}{*}{ Cerrahi } & Evet & 28 & 14 & \multirow[t]{2}{*}{0,05} \\
\hline & Hayır & 48 & 66 & \\
\hline \multirow{2}{*}{$\begin{array}{l}\text { İnvajinasyon } \\
\text { Bölgesi }\end{array}$} & İleoçekal & 10 & 4 & \multirow[t]{2}{*}{0,22} \\
\hline & İleoleal & 18 & 10 & \\
\hline USG Tanısı & $\begin{array}{l}\text { Target Sign } \\
\text { (Kisa } \\
\text { İnvaj.) }\end{array}$ & $\begin{array}{c}38 \\
(\% 50)\end{array}$ & $\begin{array}{c}60 \\
(\% 75)\end{array}$ & 0,04 \\
\hline
\end{tabular}

İki yaş altında tanı alan hastalar ile $\geq 2$ yaş hastalar arasında başvuru mevsimi açısından istatiksel olarak anlamlı bir fark yoktu $(\mathrm{X} 2=3,2 ; \mathrm{p}=0,36)$. Başvuru mevsimi ile operasyon gerekliliği arasında istatiksel olarak anlamlı bir fark yoktu $(\mathrm{X} 2=1,2 ; \mathrm{p}=0,74)$. Cerrahi tedavi gereken hastalarda invajinasyon bölgesi ile başvuru mevsimi arasında istatiksel olarak anlamlı bir fark yoktu $(\mathrm{X} 2=1,6 ; \mathrm{p}=0,96)$.

\section{TARTIŞMA}

Karın ağrısı; çocuk acilde sık karşılaşılan bir şikayettir. Kusma genellikle akut karın ağrısına eşlik eder. Kusma ağrıyı izliyorsa öncelikle cerrahi bir neden düşünülür. Aksine önce kusmanın başlayıp, daha sonra ağrının eşlik ettiği klinik durumlarda ise daha çok cerrahi dışı nedenler akla gelir. Barsak obstrüksiyonlarında olduğu gibi kusma persistan olabilir, obstrüksiyon uzun sürerse de fekaloid görünüm alabilir (3). Yenidoğan ve bebeklerde ağr1 değerlendirilmesi zorluğu nedeniyle teşhis gecikebilir. Ağrı özelliklerine hikayede dikkat edilmelidir. Ağrının başlayış şekli, şiddeti, süresi, ağrıyı azaltan ve artıran faktörler, aralıklı olup-olmaması, yayılım ve lokalizasyonu, yayılımı, organik nedenler, hastanın yaşı ve özgeçmişi, kusma ve içeriği ayrıntılı bir şekilde sorgulanmalıdır. Akut karın tanısında ayrıntılı hikaye alınması ve dikkatli fizik muayene yapılması çok önemlidir.

İnvajinasyon süt çocukluğu dönemi ve bebeklerde en s1k intestinal obstrüksiyon sebebidir. S1klığı 1,5-4 / 1000'dir. E/K: 3/2'dir erkek çocuklarda daha sık görülür. Bizim hastalarımızda ise cinsiyet açısından bir fark yoktu; hastalarımızın yarısı kız, yarısı erkekti. En sık 9 ay-2 yaş aralığındaki bebeklerde klinik bulgu verir. İki yaş altı çocuklardaki en sık akut karın sebebidir (4) Bizim hastalarımızın da yaş ortalaması 2,5 yaş idi. Gastroenterit ve ÜSYE'nin sık görüldüğü yaz ile kış aylarında daha sık görülerek mevsimsel özellik gösterir. Bizim hastalarımızın da çoğu (68 hasta ve \% 38,5) ishalin çok görüldüğü yaz aylarında başvurdu. En sık olarak \%80 ileoçekal bölgede görülür. \%95'inde herhangi nedeni yoktur ve lenfoid hiperplazi (mezenterik lenfadenit) suçlanır (5).Hastaların \%5'inde başlatıcı nokta (leading point) tespit edilir. Bunlar da sıklık sırasına göre; Meckel, polip, duplikasyon, lenfoma submukozal kanama (Henoch-Schönlein), hemanjiom, lenfosarkom ya da kistik fibrozis (KF) olabilir (6). Bizim hastalarımızın da sadece 7 tanesinde $(\% 4,5)$ başlatıcı nokta (leading point) saptand 1 ve bunlar da sıklık sirasına göre Meckel divertiküliti, apandisit ve bir hasta da karsinoid tümör olarak saptandı. Karın ağrısı atak aralarında sağlıklı görünen bebeğin, genellikle 30-60 dakika aralıklarla kramp tarzda şiddetli karın ağrıları olur. Sonrasında önce safrasız ve zamanla safralı kusmalar başlar (ileus yani intestinal obstrüksiyon gelişir). Koyu kırmızı jölemsi gayta (çilek jölesi) şeklinde kanlı dışkılama tipiktir ve barsak nekrozuna ve tedavide cerrahinin gerekliliğine işaret eder. Geç dönemde başvuran hastalarda sağ üst kadranda ağrılı kitle palpe edilir. Ayırıcı tanıda; Meckel divertikülü, apandisit, gastroenterit, inkarsere inguinal herni, volvulus ve malrotasyon düşünülür.

Kesin tanı USG ile konulur $(7,8)$. Hastalarımızın çoğunluğu (98 hasta ve \% 62,8) USG'de hedef işareti bulgusuyla teşhis ald1, 22'si $(\% 14,1) 20 \mathrm{~mm}$ ve sadece 36 hasta $(\% 23,1)>20 \mathrm{~mm}$ ölçülerek invajinasyon tanısı aldı. İki yaş altında tanı alan hastalarımızın yarısında USG'de hedef işareti olarak invajinasyon tanısı alırken bu oran $\geq 2$ yaş hastalarda 60 hasta $(\% 75)$ idi ve istatiksel olarak anlamlı bir fark vardı. $\mathrm{Bu}$ durum $<2$ yaş altındaki hastalardaki cerrahi tedavi gerekliliğinin daha fazla olması ile uyumlu bir bulguydu. Çünkü uzun segment invajinasyonların cerrahi tedavi gerektirme ihtimali daha fazladır. Cerrahi gereken hastalarımızın USG'de hedef işareti dışında, yani $\geq 20 \mathrm{~mm}$ invajinasyon tanısı alanların sayısı $28(\% 66,7)$ iken; hedef işareti bulgusuyla USG tanıs1 alanların sayısı ise sadece $14(\% 33,3)$ idi. Opere edilmeyen hastalarımızın çoğu ise (84 hasta ve \% 73,4) hedef işareti bulgusuyla USG tanısı aldı. USG'de hedef işareti ile invajinasyon tanısı alıp cerrahi gerekmeyen hastalar ile cerrahi gereken hastalar arasında istatiksel olarak anlamlı bir fark vardı $(\mathrm{p}<0,001)$. Ayrica USG'de hedef işareti ile invajinasyon tanısı alıp cerrahi gerekmeyen hastalar ile cerrahi gereken hastalar arasında başvuru mevsimi açısından da istatiksel olarak anlamlı bir fark vardı $(\mathrm{p}<0,001)$.

Hastaların çoğu ağızdan beslenmenin kesilip (iv) sıvı ve antibiyotik tedavisi başlanması ve rektal uyaranlarla (tuşe ve lavmanlar) düzelir. Kanlı dışkılamanın, generalize peritonit ve perforasyon, yüksek dereceli lökositozun olmadığı hastalarda sırasıyla USG eşliğinde hidrostatik redüksiyon; pnömotik redüksiyon; skopi eşliğinde baryum/gastrografin redüksiyon denenir. Bunlardan da en çok USG eşliğinde hidrostatik basınçlı redüksiyon tercih edilir; çünkü daha güvenli, etkin, başarı oranı daha yüksek, radyasyon riski düşüktür (9). Ameliyatsız redüksiyonda başarısızlık nedenleri; uzun süreli semptomlarda (>24 saat), ileoileal invajinasyonda, başka 
merkezde denenmiş redüksiyon olması durumunda, gelişte rektal kanama olması durumunda, $>\quad \% 5$ dehidratasyon durumundaki çocuklarda, $>2$ yaş yada $<3$ ay çocuklarda yada radyografide intestinal obstrüksiyon olması durumunda başarısız cerrahisiz redüksiyon durumu daha sık olarak görülür $(10,11)$. Bizim de cerrahi tedavi gereken hastaların çoğu ileoileal invajinasyonu olan hastalardi.

Generalize peritonit, perforasyon, kanlı dışkılama ve yüksek dereceli lökositozun olduğu gecikmiş vakalarda cerrahi tedavi esastır. Bizim hastaların ise 42 'sinde (\% 26,9) cerrahi tedavi gerekti ve bu oran literatürden daha yüksekti (12). Cerrahi tedavi gereken hastaların çoğu $<2$ yaş hastalar ve ileoileal invajinasyonu (28 hasta ve $\% 66,7)$ olan hastalardı. Cerrahide batına sağ üst transvers kesi ile girilerek manuel redüksiyon uygulanır yada rezeksiyon/anastomoz yapılır. Operasyon sonrası nüks (\% 1-4) ihtimali olduğundan hastaların postoperatif yakın izlemi gerekir. Hastalarımızın toplam 4 tanesinde (\% 2,6) cerrahi sonrası nüks görüldü. İlk hasta 9 aylık erkek, güz döneminde, ileoçekal, 50mm bölgede olan bir hasta; ikincisi 9 aylık kız, güz döneminde, ileoçekal, 50mm olan bir hasta; üçüncüsü 1 yaşında kız, yaz döneminde, ileoileal, $50 \mathrm{~mm}$ bölgede olan bir hasta ve sonuncusu ise 1 yaşında erkek, yaz döneminde, ileoileal, 50mm, 2 y1 sonra 3 yaşındayken nüks görülen bir hasta idi. Nüks hastaların tamamı medikal tedaviyle düzeldi.

İki yaş altında USG'de özellikle > 20mm ölçümle tanı alan hastaların cerrahi tedavi gerekliliği açışından diğerlerine göre daha yakın gözlemi gerekir. Opere edilmeyen hastaların ise çoğu hedef işareti bulgusuyla USG tanısı aldıkları için bunların gözleminde daha rahat davranılabilir.

Yazar Katkıları: Fikir/Kavram: M.K., M.K.; Tasarım: M.K., M.K.; Veri Toplama ve/veya İşleme: M.K., M.K.; Analiz ve/veya Yorum: M.K., M.K.; Literatür Taraması: M.K., M.K.; Makale Yazımı: M.K., M.K.; Eleştirel İnceleme: M.K., M.K.

\section{KAYNAKLAR}

1. Scholer SJ, Pituch K, Orr DP, Dittus RS. Clinical outcomes of children with acute abdominal pain. Pediatrics. 1996; 98(4 Pt 1): 680-5.

2. Reust CE, Williams A. Acute abdominal pain in children. Am Fam Physician. 2016; 93(10): 830-6.

3. Rege VM, Deshmukh SS, Borwankar SS, Kulkarni BK. Intussusception in infancy and childhood: evaluation of a prognostic scoring pattern. J Postgrad Med. 1991; 37(2): 109-14.

4. Guerron N, Figueroa LM. Intussusception and COVID-19, Successful mechanic reduction, Case Report. Glob Pediatr Health. 2021; 8: http://dx.doi.org/10.1177/2333794X211019693.

5. Majjari P, Kumar KS, Gururaja G. Jejunojejunal intussusception at birth: A rare clinical scenario. J Indian Assoc Pediatr Surg. 2021; 26(2): 131-2. http://dx.doi.org/10.4103/jiaps.JIAPS_77_20.

6. Oros-Horjus I, van der Zee DC, Vieira-Travassos D, Avis WA. Invaginaties bij kinderen: niet altijd ileocoecaal [Invagination in children: not always ileocaecal]. Ned Tijdschr Geneeskd. 2007; 151(30): 1661-4.
7. Lin-Martore M, Olvera MP, Kornblith AE, Zapala M, Addo N, Lin M, et al. Evaluating a web-based pointof-care ultrasound curriculum for the diagnosis of intussusception. AEM Educ Train. 2020;5(3):e10526. http://dx.doi.org/10.1002/aet2.10526.

8. Wiersma F, Allema JH, Holscher HC. Ileoileal intussusception in children: ultrasonographic differentiation from ileocolic intussusception. Pediatr Radiol. 2006; 36(11): 1177-81. http://dx.doi.org/10.1007/s00247-006-0311-2.

9. Eraki ME. A comparison of hydrostatic reduction in children with intussusception versus surgery: Singlecentre experience. Afr J Paediatr Surg. 2017;14(4):6164. http://dx.doi.org/10.4103/ajps.AJPS_102_16.

10. Das MK; INCLEN Intussusception Surveillance Network Study Group. Association of meteorological parameters with intussusception in children aged under 2 years: results from a multisite bidirectional surveillance over 7 years in India. BMJ Open. 2021; 11(5): e043687. http://dx.doi.org/10.1136/bmjopen2020-043687.

11. Erez I, Kovalivker M, Lew S, Lazar L, Motovic A. Ectopic gastric mucosa in a polyp causing ileo-ileal intussusception: a case report of a three-month-old baby. Eur J Pediatr Surg. 1991; 1(2): 118-20. http://dx.doi.org/10.1055/s-2008-1042472.

12. Duc VT, Chien PC, Huyen LDM, Triet PNM, Hung PT, Thuy TM, et al. Differentiation between surgical and nonsurgical intussusception: A diagnostic model using multi-detector computed tomography. Acta Inform Med. 2021; 29(1): 32-7. http://dx.doi.org/10.5455/aim.2021.29.32-37. 